\title{
Japanese clinical guideline for sleep apnea syndrome (SAS)
}

\author{
Hiroshi Kadotani ${ }^{1}$ \\ Published online: 25 November 2021 \\ (c) The Author(s), under exclusive licence to Japanese Society of Sleep Research 2021
}

Sleep apnea syndrome (SAS), which is also called obstructive sleep apnea, is a highly prevalent sleep disorder, and sleep societies have made guidelines on this sleep disorder [1-3]. More than 500,000 patients are using continuous positive airway pressure (CPAP) therapy for SAS in Japan [1]. The Japanese Respiratory Society and the "Survey and Research on Refractory Respiratory Diseases and Pulmonary Hypertension" Group of the Ministry of Health, Labor and Welfare updated the "Guideline Sleep Apnea Syndrome (SAS) Clinical Practice Guidelines" in cooperation with other related academic societies, including the Japanese Society of Sleep Research [1].

This Japanese guideline was not based on systematic reviews using the Grading of Recommendations Assessment, Development and Evaluation (GRADE) process as that of the American Academy of Sleep Medicine [2] nor endorsed another existing guideline as that of the World Sleep Society [3]. It was made to support physicians and entire medical teams to diagnose and treat SAS. Originally, 36 clinical questions were settled in Japanese and 16 of them were translated into English. Each question was answered referring to approximately 20 carefully selected recent papers and some famous and historical textbooks [1].

Each country has its own health insurance policy, and the guideline of that country should match the policy and indicate the standard medical care there. CPAP remote monitoring has been accepted and reimbursed since 2018 in Japan. This Japanese guideline remarked on the CPAP remote-monitoring system [1]. The guideline was planned to be updated every 5 years to include new pieces of evidence.

\section{References}

1. Chin K, Akashiba T, Inoue Y, Uchimura N, Ohi M, Kasai T et al. Guideline Sleep Apnea Syndrome (SAS) Clinical Practice Guidelines 2020. Sleep Biol Rhythm 2022; 20(1)

2. Patil SP, Ayappa IA, Caples SM, Kimoff RJ, Patel SR, Harrod CG. Treatment of adult obstructive sleep apnea with positive airway pressure: an American academy of sleep medicine systematic review, meta-analysis, and GRADE assessment. J Clin Sleep Med. 2019;15(2):301-34. https://doi.org/10.5664/jcsm.7638.

3. Hamilton GS, Gupta R, Vizcarra D, Insalaco G, Escobar F, Kadotani H, Guidelines Committee Members and Governing Council of the World Sleep Society. Endorsement of: "clinical practice guideline for diagnostic testing for adult obstructive sleep apnea: an American Academy of sleep medicine clinical practice guideline" by the World Sleep Society. Sleep Med. 2021;79:152-4. https://doi.org/10.1016/j.sleep.2020.12.044.

Publisher's Note Springer Nature remains neutral with regard to jurisdictional claims in published maps and institutional affiliations.
Hiroshi Kadotani

kadotanisleep@gmail.com

1 Department of Psychiatry, Shiga University of Medical Science, Seta Tsukinowa-Cho, Otsu, Shiga 520-2192, Japan 